The model builder's religion, his problems in stumbling through the recalcitrant real world, and the tenets of the ecologist's faith are the subject of this discourse by FRED BUNNELL (Foculty of Forestry, University of British Columbia, Vancouver, B.C.) based on a public lecture he gave at University College, Dublin, on July 4, 1972

\section{Theological ecology}

or

Models

and the

real world
I consider myself a theological ecologist. The term is very apt because theology is defined as: the rational interpretation of religious faith, practice and experience; the analysis, application and presentation of the traditional doctrines of a religion or religious group. Religion is simply a way of life incumbent upon true believers. During the past four years I have been engaged in the analysis, application and presentation of the doctrines of the religion of ecology both within the International Biological Program and in association with various government agencies.

\section{The religion of ecology}

I do not intend to spend much time discussing the religious tenets of ecology, but let me indicate the general gestalt of this religion as I perceive it. I am thinking of certain basic elements of the faith that are tacitly accepted and little questioned. One of these is that EVERYTHING IS SOMEHOW "IMPORTANT" AND INTEGRAL TO THE PIECE OF LANDSCAPE BEING STUDIED - that at least no biotic component of a chunk of time-space in nature is "useless" and irrelevent to understanding. Mother nature is parsimonious and nothing is wasted.

I certainly don't give ecologists all the credit for this economical approach. Diogenes of Apollonia is sometimes considered to be the first to express an authentic teleologic view of nature, but earlier Xenophon placed arguments in the mouth of Socrates which have been utilized by virtually every writer sympathetic to the designed universe argument up till the middle of the 19th century ${ }^{1}$. Aristotle's belief that "nature does nothing in vain" persists in the modern ecologist's imperturbable faith in Darwin's insight and selection. I do not want to begin an epistemological discussion now, but merely wish to make the point that unquestioned elements of this faith are responsible for two frequent failings of ecologists.

Their first failing as I perceive it is the tendency upon entering a study area to measure everything that there is time, money and imagination to measure - because it is all related and each chunk of data will provide some sort of useful insight.

Some parts are more equal than others.

The other failing is obviously related to the first. As the ecologist ponders the vast array of interrelationships he knows exists, he recognizes that an hypothesis and an elegant test of it are nearly impossible and again he gathers all data that might impinge on the relationship he is investigating; serendipity guides the way. Intuitively, he seems to recognize the statistical quandary of his world, and uses this quandary as a further rationale for gathering all data possible.

The second basic element of faith I want to mention is probably a corollary to the designed nature construct. That is: ALL PAT. TERNS ONE MEASURES ARE IMPORTANT. One may consider the expertise of the ecologist to be directed towards abstracting and defining patterns in nature. His pursuit of patterns or relationships is admirable, but again is pursued with a diligence that is also wasteful. All relationships are equally as important as study objects only if the design concept of nature truly holds and nature is indeed benevolently deterministic rather than capricious at the ecologists' level of perception.

Recently a third element of faith has entered the religion of ecologists: MATHS IS GOOD. As it has become increasingly necessary to quantify relationships many ecologists have accepted the tenets of mathematics with the same ingenuous approach they entrust to the Aristotelian concept of a designed nature. Sometimes this faith has been awarded with insightful results, sometimes with devastating results. In some instances enthusiasm and haste has shortened the spelling of GOOD by a single " $O$ ".

1/Glacken, C. J. 1967. Traces on the Rhodian Shore. Nature and culture in western thought from ancient times to the end of the 18 th century. U. Calif. Press, Berkeley, $763 \mathrm{p}$ 
Let me consider this last element of faith first and only briefly. When Carlos Castaneda' was apprenticing with the Yaqui "brujo" or medicine man, he encountered the drug peyote or mescaline. The drug introduced him to a form of perception which he could only refer to as "non-ordinary" reality. Field measurements or data collection occur in what Castaneda might call ordinary reality - a kind of time and space we are all familiar with because we move through it, eat in it, sleep in it. We feel we understand it. For most biologists, solutions to complex mathematical equations occur in non-ordinary reality - a kind of time and space that they are unaccustomed to, have never slept in, and do not always grasp intuitively. Although these two realities are essentially equally "real", they are not necessarily compatible.

Let me give some very general examples. In some theorizing about the colonization of islands the phenomena of emigration (extinction) and introduction are discussed and represented mathematically as though they were continuous functions. Thus, in the mathematical representation, although not in the accompanying verbal descriptions, we may find the unusual situation of a species having has not not arrived - it has $90 \%$ arrived. Similarly, $90 \%$ arrived on an island. It has not arrived and it another species has $90 \%$ left, disappeared and become locally extinct. There are, not surprisingly, a number of further examples in the literature discussing predator-prey relations, harvest theory and trophic efficiencies where the mathematical and biological realities are disparate. Usually the disparities result because differential equations are conveniently solved by setting one or more of the derivatives equal to zero. The mathematical solution then proceeds elegantly, often despite the fact that a derivative of zero makes no sense biologically. Integer values and discontinuous functions are less tractable mathematically, but more "realistic", if I dare use that term. Writings in the field of plant ecology are equally replete with mathematically defined noda, ordinations and associations that are only statistically and tenuously related to "ordinary reality".

I do not mention these examples to belittle specific workers; what I am trying to do is give you a good swift kick right in the old episteme. As a language, mathematics is no more trustworthy than English. Doubt may not be acceptable in religion, but it is healthy in theology. I won't discuss this third element of the ecologist's faith any further.

\section{The religion of modeling}

I wish now to extend my theological appraisal to the religion of model builders. Again I simply wish to provide a brief overview at this stage; details will follow.

First, FAITH IS THE KEY. They are devout, their faith is unwavering. They are imbued and driven by the faith that even though the approach may not

2/Castaneda, C. 1969. The teachings of Don Juan: A Yaqui way of knowledge. Simon and Schuster, New York. have worked yet, it remains one of the few paths to truth and light.

Second, BIOLOGICAL ABSOLUTES EXIST. Model builders hold perhaps more faith than many ecologists in absolutes, in ubiquitous patterns, universal ecological principles or natural laws. But ecological modelers seek these grails in only an abstract and generalized sense. Further, they have or at least had, an unshaking faith in the ecologist's ability to abstract such universals.

Third, THESE BIOLOGICAL ABSOLUTES ARE OFTEN UNTESTABLE. In seeming contradiction to his acceptance of generalized ecological principles, the model builder often does not believe that he can test these principles, or conclusively disprove their non-existence (we never prove anything statistically). He recognizes that his faith is pure and untainted by statistical exercise. He may state that "the model is of most use when it is clearly wrong".

Fourth, ERROR COMES FROM INCLUSION. AIthough supported by an imperturbable faith in general patterns, the model builder is convinced that only a small portion of the elements and patterns within a system are important as opposed to the pure ecologist's broader teleological view. In the face of Pascal's statement that "error comes from exclusion" the model builder believes that "error comes from inclusion".

He adopts the teleological view of nature to the extent of recognizing basic patterns, but remains convinced that there is a lot of garbage lying around with no real purpose - "noise" in the jargon of a communications engineer, it contains little information.

Fifth, PATTERNS NOT MAGNITUDES ARE CRITICAL. An outcome of these combined elements of faith is that the model builder assumes pattern through time and relative magnitude to be more important than absolute magnitude. He cannot statistically test the meaning of small differences in magnitude, but he can recognize when the general patterns are grossly incorrect.

So much for the model builder's religion in brief outline. I wish now to look at the naive model builder encountering the recalcitrant reality of the "real world", to discuss how his religion serves him, and how it evolved. Those junctures at which my discussion becomes rational you may consider as theology.

But first I should raise a fundamental question: What is a model? Briefly, a model is a statement of relationships. More, it is an expression of relationships between entities, actually between the states of entities.

$$
\begin{gathered}
\text { (element) hawk } \\
\text { hungry } \\
\text { (state of element) satiated }
\end{gathered}
$$

The state is frequently more important than the presence or absence of the entity. A model then is a system of state or condition indices and the relations between these entities. It does not include everything that is present in the real system. Consider the process of hunger - it can be measured 
and assigned a state on the proportion of gut filled, entirely omitting the level of blood sugar and state of the hypothalamus which are also portions of the system.

So the model is an imperfect simplification and abstraction of the real system.

It had to be to have any advantage. If the model were as complicated as the real world system being modeled, it would take as long to run, and it would cost as much in time and effort to perform experiments. Because it is an imperfect abstraction the investigator can perform manipulations that he would not dare to attempt in nature because of the cost or time involved.

A further argument for simplification lies in the state of our knowledge about most ecological systems.

Figures la and $\mathrm{lb}$ demonstrate diagrammatically some general relationships between models and the real world. A brief survey of the literature on compartment models indicates that there are between two and three $(\bar{x}=2.3)$ transfers per compartment. The addition of more compartments increases the number of interactions in some curvilinear fashion (Figure la). As ecologists recognize the importance of many more relationships than they have been able to rigorously quantify, this increase in the number of interactions is almost synonymous with an. increase in the number of assumptions. As depicted in Figure $1 \mathrm{~b}$ the first additions in detail beyond the simplest model usually provide new insights about the system's dynamics. Eventually, however, we pay a cost on the number of assumptions we have made, our understanding is confused by poorly understood interactions, and new insights are lost (Figure 1b). The location of the peak on the curve labelled "new insights" or "understanding" is a product of our initial understanding of the system. The greater our understanding, the farther the curve is shifted to the right. Unfortunately, we cannot assess the point at which a further increase in detail decreases understanding until we have passed that point.

From a look at Figures $1 \mathrm{a}$ and $1 \mathrm{~b}$ it is perhaps clearer why the model builder may say: "ERROR COMES FROM INCLUSION" (his fourth tenet of faith). Or conversely, why he has such faith in generalizable, idealized principles unencumbered by all the interactions biologically possible. He strives to abstract these principles in their bare-bones form. Our experience shows that his faith is merited. But Sir Napier Shaw ${ }^{3}$ observed this years ago: "Every theory of the course of events in nature is necessarily based on some process of simplification and is to some extent, therefore, a fairy tale". All theories or fairy tales are models; they differ from the simulation model only in that some have not been mathematically formulated. Also they typically represent only one piece or process of a large simulation model.

But more on the modeler stumbling through recalcitrant reality.

Ecosystems receive a great number of inputs which, while not entirely random, have very complicated and poorly understood distribution functions. Today's weather is often not a very good predictor of next week's weather, particularly if you are a bacterium creeping about $10 \mathrm{~cm}$ below the soil surface. Because of these largely random inputs which frequently cannot be measured or predicted, it has seemed unreasonable to construct ecological models of high predictive power.

Thus, ecological models are often judged in terms of generality and ability to guide research effort rather than on numerical predictive power or precision. Stated differently, PATTERN THROUGH TIME AND RELATIVE MAGNITUDE ARE MORE IMPORTANT THAN ABSOLUTE MAGNITUDE (the fifth tenet of faith I accredited to the model builder). Which brings us to confront the second element of faith I ascribed to ordinary ecology - ALL PAT. TERNS ONE MEASURES ARE IMPORTANT. Relationships measured through time frequently prove to be quite unrevealing of the formative dynamics of a system.

While the output of a model as represented by changes in biomass through time (Figure 2a) may be a useful means for evaluating the realism of the model, such biomass transients are relatively useless in constructing simulation models. The observation of such patterns in nature provides no more understanding of the underlying formative processes than does the observation of model output provide understanding of the internal computer language coding.

3/Shaw, Sir W. N. 1913. Forecasting weather. Constable and Company Ltd., London.

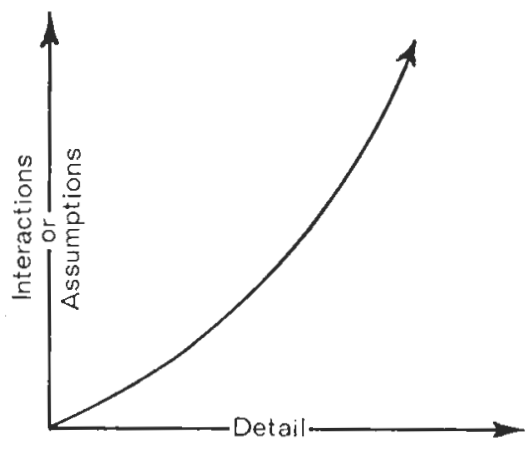

a

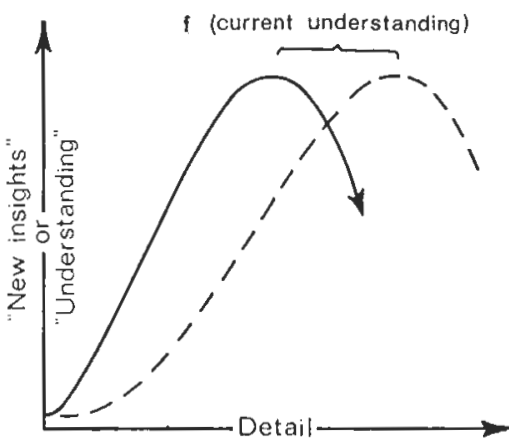

b
Fig. 1. Changes in the number of interactions and the level of new understanding as the mathemotical model incorporates more detail. 
Santayana" has written that "nature achieves permanence only through repetition". The type of functional relationship shown in Figure $2 \mathrm{~b}$ produces the permanence and represents the grails, the idealized principles, for which the model builder searches. It is when encountering data of the sort shown in Figure 2a, generally full of near random variations, that the model builder will frequently espouse the credo: "Data are background noise against which you must think". This statement does not mean that data are useless, merely that data are specific observations at a particular time and place of a generalized phenomenon. The modeler's faith exhorts him to pursue the generalized phenomenon, the biological absolutes of his second tenet of faith.

Margenaū̄ said it beautifully:

It is in the nature of concepts to be extensible, while facts can only fill dead spaces in knowledge. Concepts guide the researcher when he is looking for facts; they provide the matrix in which facts are embedded.

The model builder pursues concepts to provide the basis for the relationships he will develop; facts may be supportive but are generally specific and to that extent trivial.

It is in the separation of "concepts" and "facts" that the religions of ecologists and model builders differ most sharply. Many ecologists cling to the teleological view - nothing is superfluous, all nature has a purpose. So they sample everything they can. Some of these people feel that ecosystem studies simply mean that you gather more kinds of data.

The model builder trusts in this teleology to a lesser extent. He has to believe that there are some consistent relationships about which to develop his abstractions, but he believes that the system can be accurately described by relatively few of these relationships. While extending great faith to the importance of a few relationships, his view of the entire system is somewhat mistrustful of the capriciousness of nature. He entertains a lot of doubt while building the model. Unfortunately, this doubt frequently disappears as the model becomes more tangible and less abstract.

The difference in attitude is perhaps most ap-

4/Santayana, G. 1896. The sense of beauty. S. Scribner's Sons, New York.

$5 /$ Margenau, $H$. 1967. Integrative education in the sciences, Main Currents in Modern Thought 24: 36-41. parent in the manner in which a biologist and an experienced model builder approach the model building process. The biologist assumes it to be a tool for handling complexity and introducing more data; the modeler assumes it to be a tool for simplifying and abstracting a few important relationships out of the morass of "data". The basis of his second tenet is pragmatics.

However, despite his firm faith in a few relationships, the model builder is aware of the assumption/ detail and "insight"/detail curves (Figure 1). He is only too well aware of the near random fluctuations of nature. And he is prepared to state that he cannot validate his model. He can fuss with fitting parameters until he achieves a near perfect fit to the data, but once the model is complicated and contains many parameters there is no unique solution. Several frequently opposing sets of assumptions may produce the same result.

In many compartment models the very data that are utilized to estimate the functional relationships and parameter values are also used to "validate" the model. The models frequently fit the data beautifully, but even if there is a unique best fit the whole approach is contrary to our usual scientific integrity. By iteratively changing parameters until model output matches the data, we are searching for a means to "prove" the model. We say the model fits when it matches the data. Our entire statistical foundation, if not our common sense, states that we cannot prove an hypothesis but only disprove it. We cannot validate a model, but can only not invalidate it.

But consider if the model does not fit: what then? The computer is an idiot. It faithfully computes exactly what the modeler programmed, completely unencumbered by waffling statements and implicit assumptions. It does everything it is told to do, but only what it is told to do. If the model output is vastly different from the real world response pattern, you have learned something. Your model is wrong! There in the cold, clear light of idiocy some of your fallacious thinking stands revealed. So you review the model structure, reconsider your conceptions of the system, change a parameter value or form of a functional relationship and proceed. As long as your model output is wrong you continue to learn something. Once it fits the data you do not know what to believe. It is then predictive but it probably will provide no further insight into the dynamics of the system.

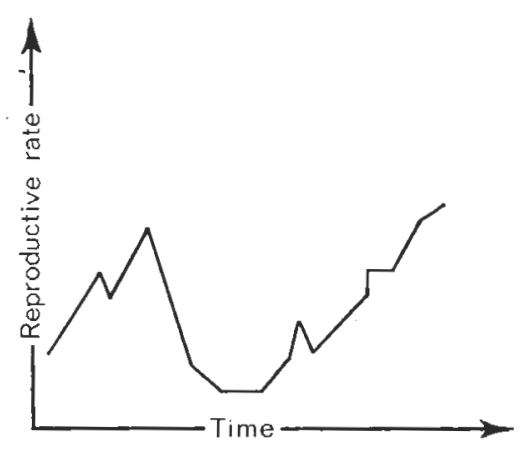

a

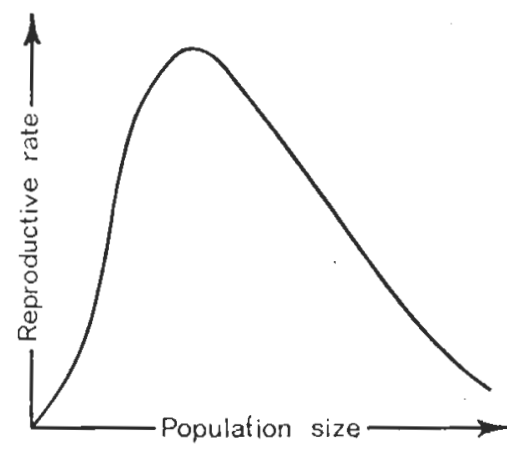

b
Fig. 2. An example of a biological variable meosured through time as opposed to its relationship with another biological variable. 
Thus, the modeler's third tenet of faith and statement "the model is of most use when it is clearly wrong". (With an attitude like that, how can we make mistakes?)

I have now mentioned underlying reasons for most aspects of the modeler's religion and tried to indicate how this religion has served him in attaining his goal - the development of imperfect abstractions. I have not mentioned the first aspect - his unflinching faith. When all he is doing is creating an imperfect abstraction of a real system, and he recognizes that he cannot rigorously evaluate his abstraction - why does he have any faith? Why model?

Some typical reasons and goals of modeling are: $1 /$ prediction or simple forecasts leading to $2 / \mathrm{ex}$ ploration of alternative management policies. By providing an abstract and simplified description of the system's dynamics, simulation models can be used to 3/ guide research efforts or outline a problem for more detailed study and 4/ compare systems of similar structure but different parameter values. But perhaps the most common reason is simply that grant money is available!

I originally defined theology as the rational interpretation of religious faith, practice and experience or the analysis, application and presentation of the traditional doctrines of a religion or religious group.

Note that this is almost precisely what mathematical modeling and systems analysis constitutes: traditional doctrines - density dependent effects upon reproductive rate, functional response of predators to prey density - are presented, described and analyzed within a framework that is almost certainly more rational and coldly analytical than our usual verbal discussions. The modeling process strips many of the implicit assumptions from our concepts, and by default - guided by the impenetrable, unnerving idiocy of the computer we rationally appraise relationships within a dynamic framework.

But what of the modeler's inability to rigorously test the model - how rational is this?

In the strict sense, sensitivity analysis is impossible because ecological models are almost certain to be full of non-linearities, thresholds, and time lags that prohibit steady-state analyses. But we

\section{EDWARD FELLOWS}

FORESTRY \& FOREST PRODUCTS CONSULTANT

$$
\begin{aligned}
& \text { P.O. Box 354, } 461 \text { King St., MEMBER: } \\
& \text { FREDERICTON, N. B. } \\
& \text { Registered Professional } \\
& \text { Forester (N. B.) } \\
& \text { Conadian Institute } \\
& \text { of Forestry } \\
& \text { Forest Products Research } \\
& \text { Society, Etc. } \\
& \text { INDUSTRY DEVELOPMENT - FOREST PRODUCTS - } \\
& \text { ECONOMIC FOREST POLICY \& ADMINISTRATION }
\end{aligned}
$$

can do some things. Stability regions can be explored through phase diagrams. Stability regions comprise the set of starting values for which the system will not break down. We can employ sensitivity analyses of various sorts as described by Walters ${ }^{\text {i }}$ and others:

Input-output sensitivity: by varying forcing functions. If we fertilize a lake or forest what happens to the fish production or wood fibre production? Does the additional nutrient disappear into a nonproductive side-chain such as zooplankton or understory vegetation? Is the additional instability worth the cost? What happens if we dump $y$ tons more pulp mill effluent into a river?

Relative sensitivity: sensitivity of model components to one another, measured either as $1 /$ change in equilibrium or average values of one with another or 2/ stability of one as a function of stability in another. An example might be the exploration of litter accumulation in a nutrient cycling model: how sensitive is it to plant uptake rates or microorganism feeding rates? Which components of a system are sensitive to which others; that is, what is their relative importance?

Model integrity: overall performance of the model (stability, equilibrium values) to changes in parameters and functional relationships. This kind of sensitivity analysis is particularly valuable in suggesting areas of more careful field measurement and experimental work. Key components or interactions may become apparent.

In short, sensitivity analysis is useful when you do not know the strategy of the system, or what strategy to take to achieve a particular end. It is not rigorous but it is likely valuable, and the approach is at least somewhat rational.

Thus, the modeler — with a varying mix of cerebral conviction and visceral response - maintains his faith in the modeling exercise. As armchair theologists we can acknowledge that he uses the model as a device or a tool to keep him distinct from that group so aptly described by St. Augustine as those "who saw the effect but not the cause".

6/Walters, C. J. 1971. Systems ecology: the systems opproach and mathematical models in ecology, p. 276-292. In Odum, E. P. (Ed.) Fundamentals of ecology. 3rd edition, W. B. Saunders Co., Toronto.

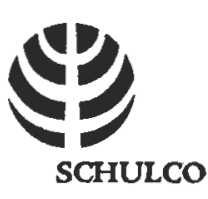

C. D. SCHULTZ \& COMPANY LIMITED SCHULTZ INTERNATIONAL LIMITED

FORESTERS \& CONSULTING ENGINEERS ECONOMISTS \& BIOLOGICAL SCIENTISTS

INTEGRATED RESOURCE DEVELOPMENT ENVIRONMENTAL IMPACT STUDIES

325 Howe Street Cable: "SCHULCo" Telex: 04-53385 Telephone: (604) 684-7336 SINCE 1944 